\title{
Seeing eye-to-eye on ICT: Science student and teacher perceptions of laptop use across 14 Australian schools
}

\author{
Simon J. Crook, Manjula D. Sharma, Rachel Wilson and Derek A. Muller \\ University of Sydney, Australia
}

\begin{abstract}
As schools start investigating and investing in the idea of 1:1 iPads and tablets, are there any lessons that can be learnt from recent 1:1 laptop deployments? In Australia, since 2008, 1:1 laptops have been introduced into every secondary school. This study reports on a survey designed to investigate frequency and type of laptop use, and the alignment of teacher and student perceptions of that use. Data was obtained from 14 secondary schools from the Catholic Education Office Sydney, involving responses from 1245 Grade 10 science students and 47 science teachers. As part of the analysis, bubble graphs are used to visually represent a teacher's alignment/misalignment with their students' self-reported practices. Results show student and teacher perceptions of use were usually relatively aligned though sometimes very contrasting. The alignment was measured with the use of a 'Misalignment Index'. Three distinct types of teacher/student alignment or misalignment emerge from a graphical analysis of the data. Of the teachers and students sampled, some $30 \%$ of teachers were highly aligned, $55 \%$ had medium alignment and $15 \%$ were badly misaligned with their respective students. Potential uses of the Misalignment Index and analysis tools are discussed.
\end{abstract}

\section{Introduction}

In November 2007, 'A Digital Education Revolution' Policy Document was released stating an intention to "provide world class information and communications technology (ICT) for every secondary student in years 9 to 12", (Rudd, Smith, \& Conroy, 2007, p. 1) "ideally equipping every student with a laptop" (Australian Broadcasting Corporation, 2007). In February 2008, all secondary schools were informed that they could apply to participate in the Digital Education Revolution (DER) (DEEWR, 2008a; Gillard, 2008a).

The Catholic Education Office (CEO) Sydney is responsible for the management of the 147 systemic Catholic schools which educate more than 65,000 students in the Archdiocese of Sydney (CEO Sydney, 2012). Following DER guidelines, CEO Sydney decided to issue a laptop to every Grade 9 student for 4 years. The first CEO Sydney school issued their Grade 9 students with laptops in September 2008, with the other Round 1 schools (DEEWR, 2008b; Gillard, 2008b) doing likewise shortly after. The Round 2 schools received their first machines in mid-2009 (Gillard, 2009). Overall, for CEO Sydney, this meant laptops would be provided to over 4,500 students per year for 4 years i.e. over 18,000 students. Whereas the students' laptops were paid for by Federal Government funding, the teachers' laptops were paid for (unexpectedly) by the individual schools.

The students and teachers in this sample would have had 1:1 laptops for either one or two years at the time of data collection. This paper reports on the perceptions of science students and teachers on the use of the laptops.

\section{Research Context and Purpose of Study}

Several studies and meta-analyses have investigated the effect of 1:1 laptops on teaching and/or learning. Studies looking primarily at teacher use of laptops have found a variety of benefits and challenges (Donovan, Hartley, \& Strudler, 2007; Garthwait \& Weller, 2005; Owen, Farsaii, Knezek, \& Christensen, 2005; Windschitl \& Sahl, 2002; Zucker \& McGhee, 2005). Some of the studies around the impact on teaching and learning have reported positive impacts (Bebell \& O'Dwyer, 2010; Greaves, Hayes, Wilson, Gielniak, \& Peterson, 2010; Gulek \& Demirtas, 2005; Ingram, Willcutt, \& Jordan, 2008; Lin \& Wu, 2010; Silvernail \& Lane, 2004; Zucker \& McGhee, 2005). Similarly, some meta-analyses have reported overall positive effects of 1:1 laptops on teaching and learning (Penuel, 2006). 
Investigating the impact of technology in general there have been various studies and meta-analyses. Several studies report positive impacts on teaching and learning (Chowdry, Crawford, \& Goodman, 2009; O'Dwyer, Russell, Bebell, \& Seeley, 2008; OECD, 2010). Similarly, several meta-analyses report overall, if somewhat minor, positive impacts of technology on teaching and learning (Goldberg, Russell, \& Cook, 2003; Kulik, 2003; Moran, Ferdig, Pearson, Wardrop, \& Blomeyer, 2008; U.S. Department of Education, 2010; Warschauer \& Matuchniak, 2010).

However, a few studies have highlighted negative impacts of technology on student performance (Vigdor \& Ladd, 2010) and some meta-analyses state that the various studies conducted raise more questions than provide answers (Valiente, 2010; Weston \& Bain, 2010). Increasing student access through 1:1 laptop ratios does not necessarily increase student usage (Larkin \& Finger, 2011).

In his synthesis of meta-analyses, Hattie (2009) states, regarding the various studies of the impact of technology on student performance:

the majority of studies in this area are about teachers using computers in instruction and there are fewer studies about students using them in learning. That is, often the studies compare teaching in classes with and without computers (of some variant) rather than comparing students learning in different ways when using computers (p. 221).

Elaborating on this theme, Fullan (2011) states:

The notion that having a laptop computer or hand-held device for every student will make her or him smarter is pedagogically vapid ... Without pedagogy in the driver's seat there is growing evidence that technology is better at driving us to distraction, and that the digital world of the child is detached from the world of the school (p. 15).

None of the papers, in our search to date, have examined students' reported use of laptops and how this compares with their teachers' practices and perceptions of the students' use. However, Niles (2006) did compare teacher and student perceptions of the impact of 1:1 laptops and Burgad (2008) investigated teacher, student and parent perceptions of 1:1 laptops and academic performance. Niles found that there was a paradigm shift in terms of classroom dynamics, communication and belief around the impact of 1:1 laptops from both teachers and students. Burgad found that students, teachers, and parents all perceived increased student engagement, motivation, and organization, along with improved research, writing, and editing skills. In fact, these laptop students also experienced significant gains in mathematics though significant dips in reading and language arts.

A fundamental question underpinning this paper is 'do teachers need to bring their own laptop to class?' The authors would argues 'yes'. The provision of staff laptops has been demonstrated to empower teachers to move from "didactic instructional approaches toward more student-centred, project-based lessons" (Windschitl \& Sahl, 2002, p. 178). A teacher's laptop is a hub for learning in the classroom (Parr \& Ward, 2011). Similarly:

teachers with laptops are integrating ICT into their pedagogy and offering students a more varied and accessible curriculum (Cowie, Jones, \& Harlow, 2011, p. 253).

In his meta-analysis of 52 studies on the effects of computer-assisted instruction versus traditional instruction on students' achievement, Liao (2007) found that the mean effect size was 0.55 i.e. more effective. Regarding the local context, since many of the science laboratories and classrooms in the schools surveyed have interactive whiteboards, the mobility of a teacher's laptop would allow for the inclusion and individualised use of this technology, particularly as teachers move between classrooms.

The aim of this study was to consider the various facets of the self-reported frequency of laptop use to determine the relative alignment or misalignment between the practices and requirements of teachers and their respective students' reported practices and laptop use. Rather than simply measure and focus on teacher and student efficacies with using laptops and technology as in previous studies, we wanted to see if there was merit in measuring the relative alignment of the teachers' practices and requirements of their students, and the students' reported practices and use. The motivation for this was to accommodate those 
teachers and occasional students that state "my current methods work, why should I change?; if it ain't broke, don't fix it". That is, how would classes where the teachers do not require students to use their laptops (and the students comply) compare with those classes of high teacher requirement and high student use? Also, can we identify the instances of teachers requiring that their students use laptops a lot and the students self-reporting that they do not, and vice versa? Do students really use the laptops as often as teachers require them to for particular tasks? Are teachers 'in tune' with their students?

\section{Method}

\section{Sample}

The sample of 14 schools reported on in this study was drawn from the 16 secondary schools of the Southern Region of CEO Sydney. These schools range from the lowest socio-economic status (SES) with significant fractions of students within the English as a Second Language (ESL) program to some of the highest SES with low ESL secondary schools in CEO Sydney. All 14 schools are comprehensive and non-academically-selective. Eight schools are single-sex and six are co-educational schools. Four schools cater for Grades 7-10 and ten schools cater for Grades 7-12. In terms of the size of schools, in 2010, the Grade 10 cohorts ranged in size from 108 to 218 with the number of practicing Grade 10 science teachers ranging from 4 to 8 per school.

\section{Questionnaire Design}

The questionnaire was constructed for this particular study around the 'use' of laptops rather than how they were used or how best they could be used. In this research, 'use' refers to frequency of use. This is considered the first step prior to probing how they are used which will be discussed in a follow up report. Draft questions were developed by the authors in view of extant literature. The draft questions were then critiqued by a group of six educational experts, two with several years of experience and the others with more than 20 years of experience each. The draft questions were modified slightly and the final questions are shown below.

The teacher questions read:

T1 How often do you bring your laptop to School?

T2 How often do you bring your laptop to your Year 10 Science class?

T3a How often do you use your laptop in this Science class?

T3b How often do you require your students to use their laptop in this Science class?

T4 How often do you require your students to use their laptop for Science homework?

T5 How often do you do you require your students to use their laptop in Science assessments?

The student questions read:

S1 How often do you bring your laptop to School?

S2 How often do you bring your laptop to this Science class?

S3 How often do you use your laptop in this Science class?

S4 How often do you use your laptop during Science homework?

S5 How often do you use your laptop during Science assessments?

Both teacher and student respondents had to answer using a 5-point Likert scale: $1=$ never to 5=always.

The survey items were almost identical for purpose of comparison i.e. $\mathrm{T} 1 \leftrightarrow \mathrm{S} 1 ; \mathrm{T} 2 \leftrightarrow \mathrm{S} 2 ; \mathrm{T} 4 \leftrightarrow \mathrm{S} 4$ and $\mathrm{T} 5 \leftrightarrow \mathrm{S} 5$. It is important to note that the comparisons $\mathrm{T} 1 \leftrightarrow \mathrm{S} 1$ and $\mathrm{T} 2 \leftrightarrow \mathrm{S} 2$ contrast the self-reports of the behaviours (practices) of both teachers and students. However, it is also important to note that comparisons $\mathrm{T} 3 \mathrm{~b} \leftrightarrow \mathrm{S} 3, \mathrm{~T} 4 \leftrightarrow \mathrm{S} 4$ and $\mathrm{T} 5 \leftrightarrow \mathrm{S} 5$ contrast the requirements (expectations) by teachers on student use with the self-reported student use. (Since a fundamental focus of this study was to compare the requirements of teachers on student use with the reported use by the students themselves, T3b (rather than T3a) was compared with S3).

\section{Procedure}


The questionnaires were administered online via Google Docs 'Forms' for simplicity. This eliminated the cost, time and errors involved in transcription, while maintaining confidentiality of the data. The questionnaires were administered to Grade 10 science teachers and students from the participating secondary schools in August/September 2010 ahead of the 2010 statewide School Certificate examinations. The timing was such that there was a window of opportunity providing access to both students and teachers.

The overall return rate was 47 teachers $(64 \%)$ and 1245 students $(60 \%)$. However, the number of students whose teachers also responded was 815 (39\%). In addition, due to some non-Year 10 teachers responding or minimal responses from a teacher's students, some 40 teachers $(55 \%)$ are considered in this paper. Given the normal response rates from online surveys of around $25 \%$ (Kaplowitz, Hadlock, \& Levine, 2004 ), the response rates in this study of over $60 \%$ combined with the large sample sizes and range of schools mean that diversity in the sampling is captured.

\section{Results and Discussion}

The profile of a particular class' laptop use was compared with that of the class teacher using 'bubble' graphs; see Figure 1(a-c).

Figure 1 shows the students in patterned bubbles and the teacher as a solid bubble for each question on the survey ( 1 to 5 on the $\mathrm{x}$-axis). The $\mathrm{y}$-axis represents the Likert scale responses. Bigger bubbles mean more students for particular responses. Figure 1(a) shows that the students in school 1A with teacher 2 (that is teacher 1A2), bring their laptops to school (first column of patterned bubbles) anywhere from about half of the time to all of the time, with the majority bringing all of the time. Likewise, the teacher (small solid bubble) brings her laptop all of the time to school. This teacher appears well aligned with her students in all aspects except with regard to use of laptops for assessments. Compare this with her two corresponding colleagues from the same school, teacher 1A4 in Figure 1(b) and teacher 1A3 in Figure $1(\mathrm{c})$.

Teacher 1A4 has an identical profile to 1A2. Though his students use their laptops even more frequently, particularly in class and for homework, teacher 1A4 is still very aligned if not more so than teacher 1A2. However, as can be seen in Figure 1(c), the practices and requirements of use by teacher 1A3 do not coincide with his students' practices and self-reported use, particularly with regard to bringing their laptops to school and science class in the first place. 
(a)

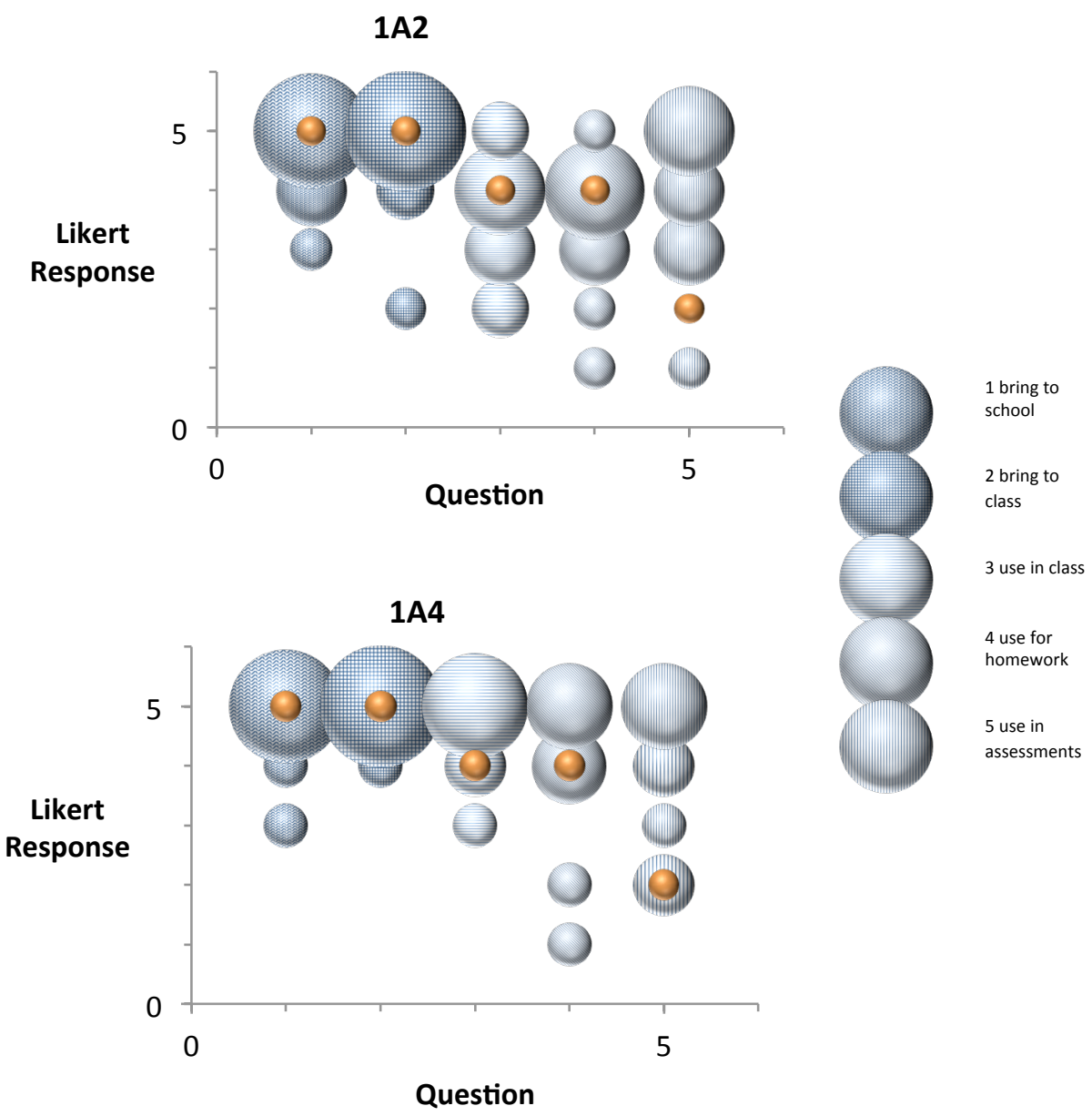

(c)

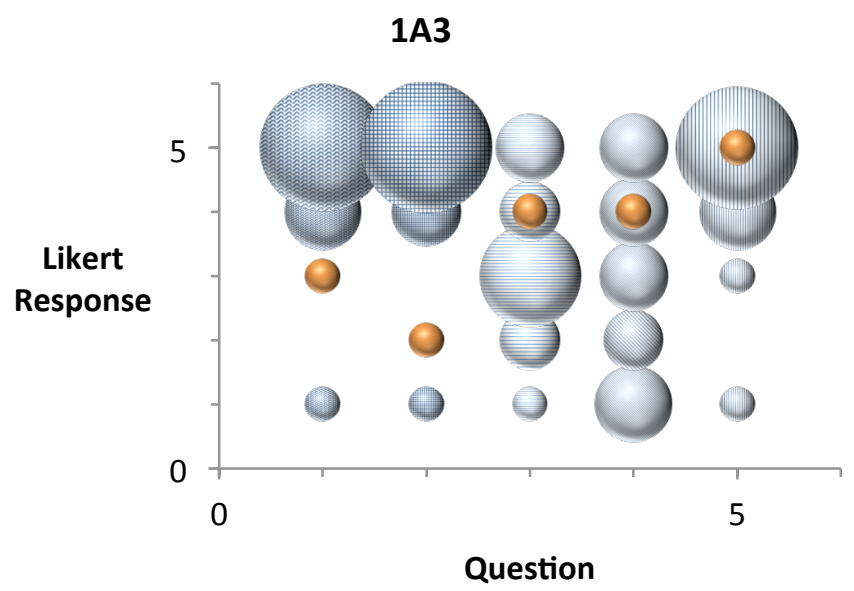

Figure 1. Bubble graphs for teachers 1A2, 1A4 and 1A3 and their classes showing Likert response versus question. 
One could argue that teachers do not necessarily need to bring their laptops to class in order to facilitate the students' learning with their own laptops. However, as was highlighted in the introduction and research context presented earlier in this paper, whereas the student laptops were paid for by Federal Government funding the teacher laptops were paid for by the individual schools. As such there is the expectation that teachers both bring their laptops to school for their own administration e.g., checking email and daily notices, plus bring them to class to model good practice to the students and offer a more varied and accessible curriculum. Essentially the underlying philosophy is that laptops are integral components rather than add-ons. A "school community deliberately and systematically uses its rules to embed its big ideas, values, aspirations, and commitments in the day-to-day actions and processes of the school" (Weston \& Bain, 2010, p. 12) e.g., around bringing one's laptop to school and class. To ensure that the DER worked in its schools, CEO Sydney provided every secondary school with wireless access plus provided substantial professional development opportunities for teachers as a system and more locally within individual schools. Ultimately, explicit expectations were given by CEO leadership and principals to teachers regarding the integration of laptop use in the daily teaching and learning practices to capitalise on opportunities provided by the DER. Teacher 1A3 could be deemed non-compliant with such practices and expectations. It should be noted however, that despite this the students of teacher 1A3 are very compliant with school expectations on bringing their laptops to school and class. It can also be observed that the students of teacher 1A3 have greater variance in their use, particularly in class and for homework, than the students of teachers $1 \mathrm{~A} 2$ and $1 \mathrm{~A} 4$.

Such bubble graphs were generated for all 40 teachers considered. An observation of all bubble graphs demonstrated that patterns emerged for questions 1 to 4 . Question 5, regarding student laptop use for assessments, had substantial, somewhat random variations, thereby appearing anomalous. It was decided that this question was ambiguous due to a lack of agreement on what constitutes an assessment. For example, some assessments would actually have been examinations without laptops yet many students and some teachers stated they always used laptops in assessments. As such, when the 'Misalignment Index' (MI) was generated, Question 5 was excluded.

The MI was created to measure the variations between teacher practices and requirements, and student practices and use that could be observed in the bubble graphs. The simple calculation summed the moduli of the differences between a teacher and his/her students for similar questions as shown in Equation 1.

$$
\mathrm{MI}=\Sigma|\mathrm{T}-\mathrm{S}| \quad \text { Equation } 1
$$

The MIs ranged from 1.0 to 6.1 with an average of 2.7 and a standard deviation of 1.3 . Of the 40 classes, some $30 \%$ showed high alignment of laptop use (MI of $0-1.9$ ), 55\% were moderately aligned (MI of 2.03.9 ) and $15 \%$ of classes were quite misaligned (MI of 4.0+ i.e. the equivalent of a disparity of at least 1 in each of the 4 questions). A graph of the teachers' MIs versus their average Likert responses can be seen in Figure 2 (coded by how many years' experience they have of teaching students with laptops).

As can be seen in the trend line (for all teachers) in Figure 2, those teachers with the highest average Likert response tended to have the lowest MI. This implies that those teachers that exhibited high usage and required high usage by their students are most aligned with their students i.e., their students report similarly high usage. Whereas, those with lower average Likert responses tended to have higher MIs. This would imply the teachers that report lesser use and have lower required student use are less aligned i.e., the students report greater use than the teacher. It should be noted that only one teacher gave an average Likert response less than 3 (at 2.5) i.e. less than the median Likert response. Consequently, though we hypothesised the existence of relatively lower use teachers, these teachers in fact report semi-regular use as a minimum. This is important since it demonstrates in fact no teachers reported minimal use throughout. 


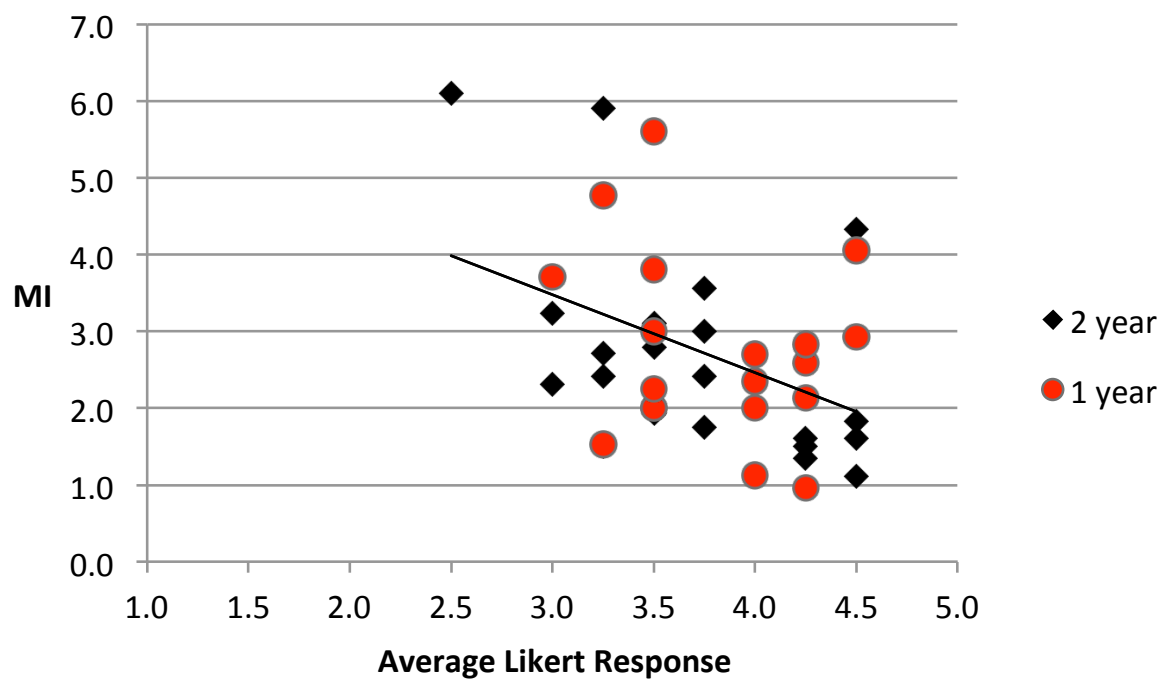

Figure 2. A graph to show MI versus Average Likert Response for all teachers.

(a)

$1 \mathrm{H} 3$

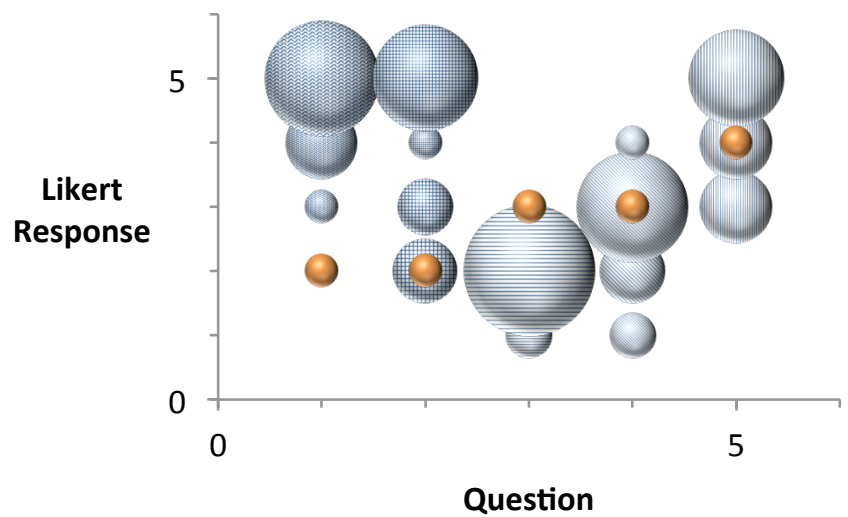

(b)

2J1

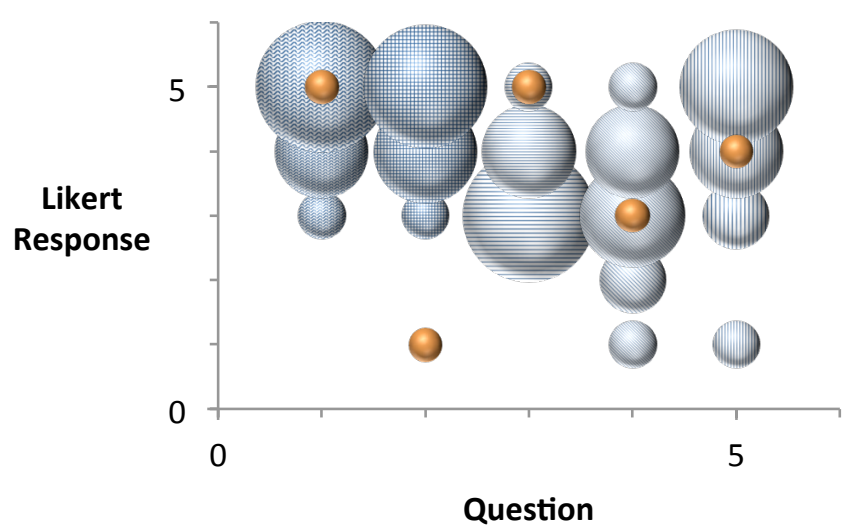

4 use for
homework

5 use in

assessments

Figure 3. Bubble graphs showing high misalignment. 
It should be noted that the laptops were deployed over a couple of years. Round 1 teachers would have had two years' experience of teaching students with laptops at the time of sampling (denoted as circles in Figure 2). Round 2 teachers would have had one year's experience at the time of sampling (denoted as diamonds in Figure 2). The distributions for the two rounds appear quite similar with no obvious difference in trend between MI and average Likert responses within this small timeframe. Also, considering MI specifically, there are similar numbers of Round 1 and 2 teachers within each of the low (0-1.9), medium (2.0-3.9) and high misalignment (4.0+) ranges. This would appear to indicate that an extra year's experience and possible embedding of practice, even at such an early stage, might have little impact on teacher practice and perception. Although technology necessitates that "teachers change their pedagogy for learning to become relevant and meaningful for students" (Fullan \& Smith, 1999), some teachers buy into new paradigms with vigour immediately and some refuse, or only move on their own terms.

The reduction to a single value given by the MI removes information but does provide a mechanism for comparison. As already mentioned, finer detail can be observed in the bubble graphs. Bubble graphs for two of the teachers with the highest alignment (lowest MI) have already been given in Figures 1(a) and 1(b). The bubble graphs for the two most misaligned teacher/students with the highest MI (aside from $1 \mathrm{~A} 3$ in Figure 1(c)) can be seen in Figure 3.

Regarding the misaligned teacher/students it is interesting to note in Figure 3(a) that teacher 1H3 rarely brings her laptop to school or class but her students do so most if not all of the time. In Figure 3(b), the most misaligned teacher $2 \mathrm{~J} 1$, always brings his laptop to school but never brings it to science class. This raises the question, does teacher $2 \mathrm{~J} 1$ only use his laptop for administration rather than teaching and learning (Cuban, 2001). Somewhat ironically, 2J1 expects his students to use their own laptops every lesson, whereas they state they only use it half of the time! With the requirement asked of the students at odds with the disposition of the teacher it is not surprising that the self-report of student laptop use is less than expected (Vannatta \& Fordham, 2004).

Further analysis of the results was achieved by plotting the average student response against the respective teacher's response for each question. The results can be seen in Figure 4(a-d). Every graph in Figure 4 includes a solid line for $y=x$, i.e., the line of alignment for teachers and students. In addition, 2 dashed lines are present to border student responses within \pm 1 of the line of alignment with their respective teachers. Falling beyond \pm 1 of the line of alignment would be considered misaligned. There are therefore two regions of misalignment: the top-left triangle bordered by the +1 dashed line and the $y-$ axis; and the bottom-right triangle bordered by the -1 dashed line and the $\mathrm{x}$-axis (see Figure 5).

As can be seen in Figure 4(a), every teacher apart from 3 brings their laptop to school all of the time. Every class of students by and large brings their laptop to school nearly all of the time apart from one outlier. It can be observed that despite most teachers and students bringing their laptops to school all of the time it is a different story when bringing their laptops to science class (Figure 4(b)). This is particularly the case for teachers. All data points within the top-left triangle bordered by the +1 dashed line and the y-axis are where the class teachers are far less compliant than the students within their classes. In the instance of bringing laptops to science class this accounts for 13 or $33 \%$ of the teachers. There are no points in the bottom-right triangle that would have indicated relatively non-compliant students. The question regarding the practice of bringing laptops to science classes demonstrates the greatest misalignment.

Figure 4(c) shows that in terms of use of laptops in class, the relative frequency of use by the students and the required use by the teachers have the greatest alignment. There are many that fall within high-use alignment $(T=4, S=4 \pm 1)$, many within medium range $(T=3, S=3 \pm 1)$ and interestingly three within low-use alignment $(T=2, S=2 \pm 1)$. There are no points within the top-left triangle meaning there are no instances of low teacher requirement paired with high reported student use. There are 5 points in the bottom-right corner indicating that these teachers require far greater student use of laptops in their class than is actually the case according to the students themselves. Figure 4(d) looks very similar to Figure 4(c) though there is a tendency towards lesser required use of laptops for homework by teachers and reported use by students. There is one outlier in the top-left triangle indicating a much lower requirement by the teachers compared to the students' reported experience of using laptops for homework. There are 6 points in the bottom-right triangle where the teacher requirement is far greater than the self-report by students. 
(a)

Bring to School

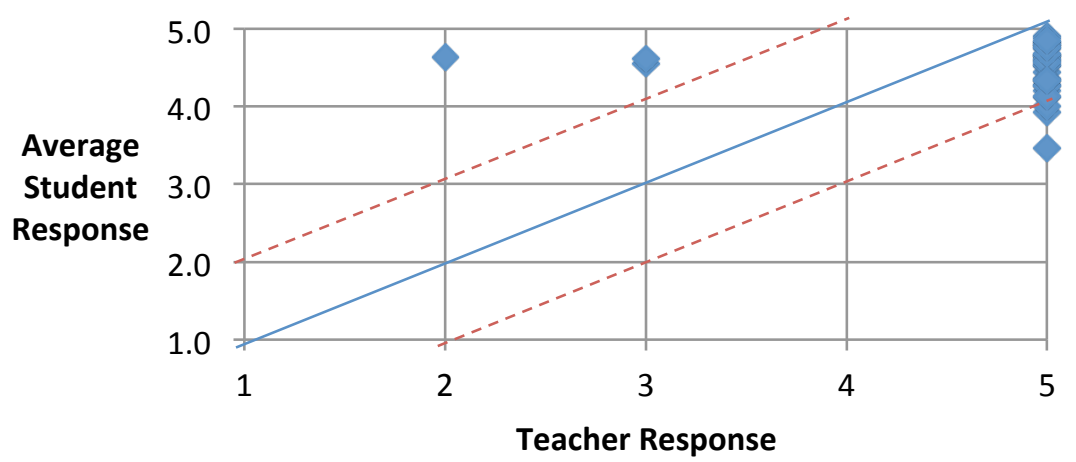

(b)

Bring to Science

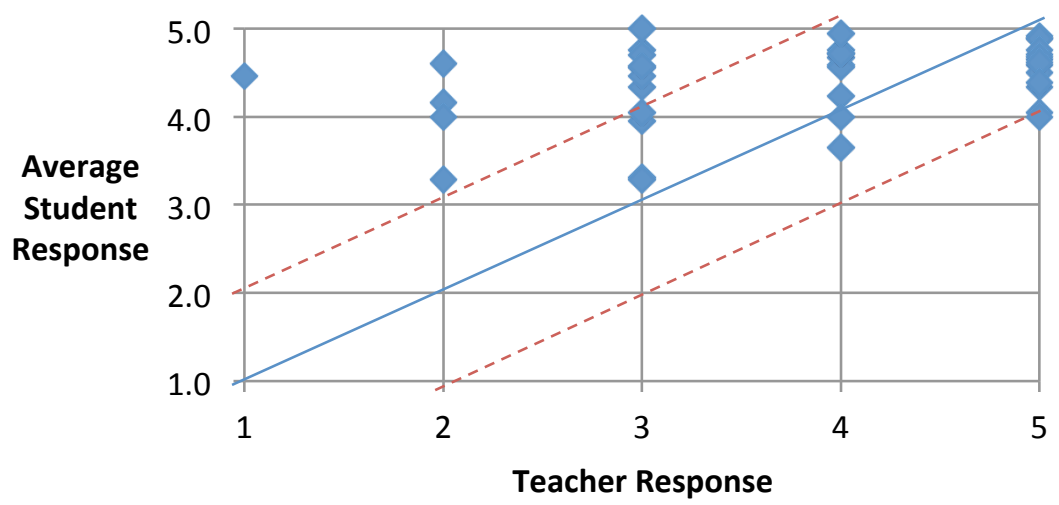

(c)

Students' Use in Class

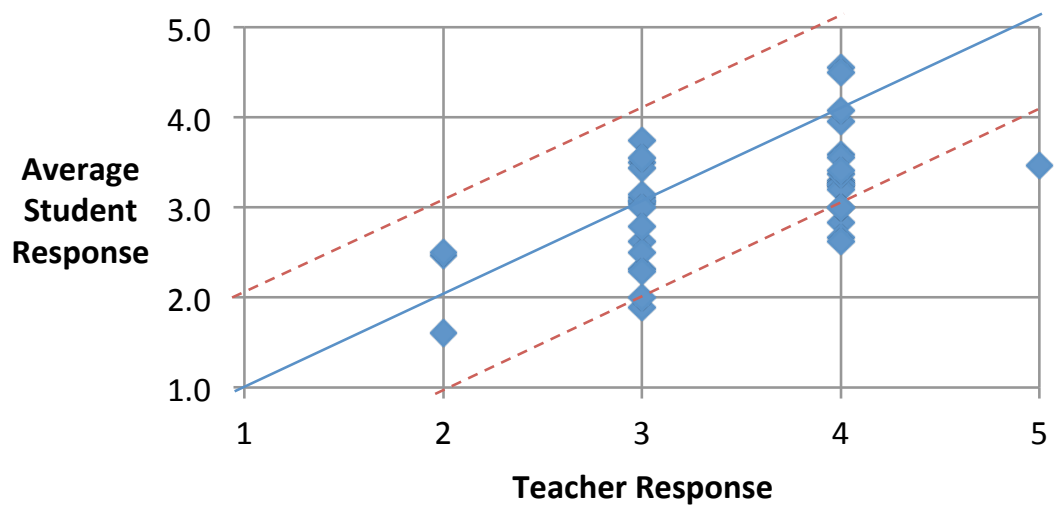

Figure $4(a-c)$. Comparing student and teacher responses. 


\section{Students' Use in HW}

(d)

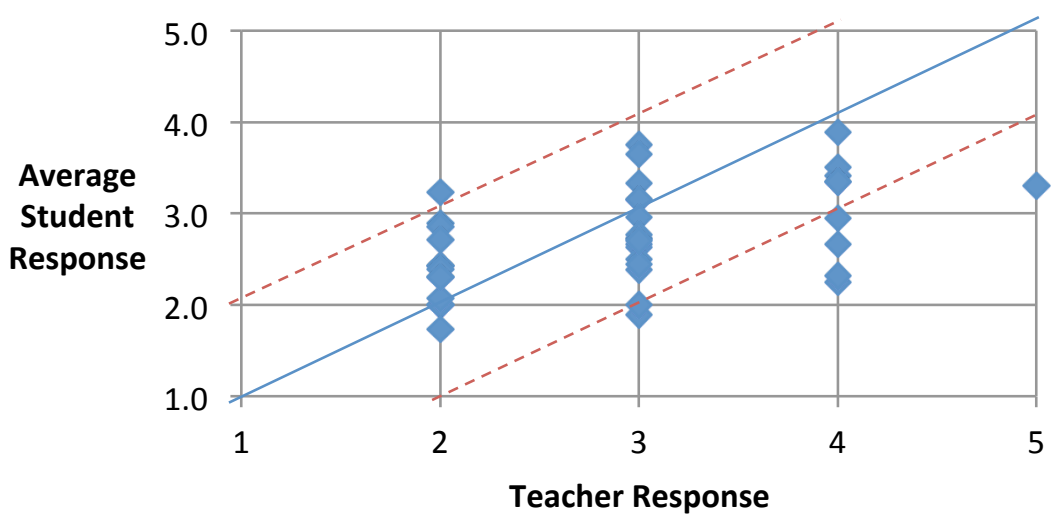

Figure $4(d)$. Comparing student and teacher responses.

\section{Implications}

The question of how the above analysis methods can be used and what utility they offer emerges. The answer is at two levels. First, the analysis methods provide resolution and detail that can be used at the school management level to identify and learn from good practice. Highly aligned teachers (in terms of both behaviour and expectations) can be identified and hence observed. It is hypothesised that one might learn from the highly aligned teachers' classroom management and pedagogical skills with (and without) technology. Further research must be undertaken to observe such teachers and discover if this is in fact the case. The second level is obtained by taking the analysis a step further. As in Figure 4, every class of students can be plotted against their respective teachers on a graph for any variable that might be investigated. Figure 5 provides an empirical graph highlighting the different areas of alignment and misalignment, applicable for any context that might be surveyed. The teachers could be colour-coded to represent e.g. schools, years of practice or other categorical features. Broader patterns might then emerge in terms of which schools and/or categorical features need addressing to improve teacher-student synergy and ultimately student learning outcomes.

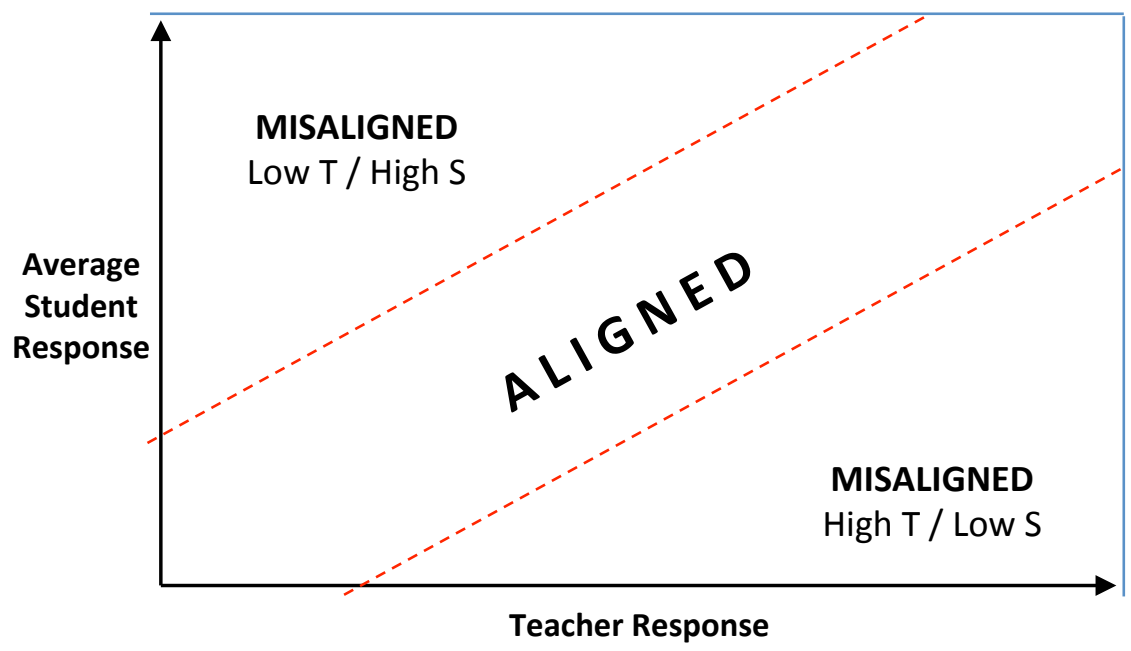

Figure 5. Graph demonstrating 3 distinct zones of student/teacher alignment.

The ability to map teacher/student alignment, as measured by this relatively easy and transparent (to both the teacher and policy maker) mechanism at the very basic level of 'use', provides a powerful tool for the assessment of professional development initiatives and classroom culture (Supovitz \& Turner, 2000). In 
the case of the Australian Government's substantial investment in the Digital Education Revolution and CEO Sydney's deployment of this initiative, analyses such as those described in this paper would assist policy makers and educators in assessing the level of classroom cultural change (Hargreaves, 1994) taking place and identifying where further support is required such as targeted and personalised professional development for specific teachers. In some cases the misaligned teachers (in terms of behaviour and expectations) may have good practices that are not captured by this study. On the other hand, the underlying philosophy to integrate laptops into classroom practices starts with good use of computers. Strategic programs to couple good practices with optimum use and hence integration of laptops can then be designed and implemented to suit local regional and school contexts.

Other questions that arise include how does any misalignment between teacher practice and requirement, and student reported practice and use impact on teaching and learning? Do teachers that think students rarely use (or need to use) laptops rarely plan lessons with them? These are aspects that could be investigated in future work.

This research should add a nuance to the body of literature around how teacher attitudes and use of technology affect student use (Miller, 2008; Ottenbreit-Leftwich, Glazewski, Newby, \& Ertmer, 2010; Vannatta \& Fordham, 2004; Windschitl \& Sahl, 2002).

\section{Future Work}

The obvious extension of this study is to investigate how the students of the highly aligned and misaligned teachers performed i.e., investigate any possible relationship between laptop usage, MI and educational outcomes. With the first external examination data in the DER 1:1 laptop context obtained for the 2009 School Certificate (SC) and 2011 Higher School Certificate (HSC) examinations there is a unique opportunity to assess the impact of 1:1 laptops on student performance. Each of these epochs has the unique dichotomous scenario where half of the candidature will have sat having been schooled with laptops and half without. Trend and value-added data will be available as students involved in the DER perform these examinations over subsequent years with the final 2012 DER Grade 9 cohort undertaking its HSC in 2015 allowing for longitudinal study. (However, in August 2011 it was announced that the School Certificate would be discontinued after 2011 (Piccoli, 2011)). More appropriately, using the survey data, further study could examine type of use e.g. high/low-order activities, professional development and calculate teacher and student efficacies. Ultimately, by comparing the reported use by students and teachers to generate respective efficacies and Misalignment Indices then cross-referencing these with standard examination results, coherent data should ultimately be obtainable to perform a multiple regression to assess the impact of 1:1 laptops on student performance.

\section{Conclusion}

We set out to investigate the reported use of laptops in 14 schools in Sydney by science teachers and students. Patterns of use and variation in the alignment between teacher and student practices and perceptions were identified using a 'Misalignment Index' developed in this context. It was found that some $30 \%$ showed high alignment of practices and perceived laptop use, $55 \%$ were moderately aligned and $15 \%$ of classes were quite misaligned. The study provides methods of identifying high alignment of teachers and students. This may aid schools in identifying and learning from highly aligned staff and also identifying where there is significant misalignment and hence where strategic support may be required.

Some $15 \%$ of teachers would appear to be quite out of touch with their students regarding laptop use. This raises the question of what does this mean for the education of these students? The answer is that further study is needed to investigate if such misalignment (or alignment) has any bearing on lesson planning, teaching, learning and ultimately student performance.

\section{Acknowledgements}

This project has human ethics approval from CEO Sydney and The University of Sydney. We are extremely grateful for the support, participation and openness from the teachers and students of the participating schools and the cooperation and support of CEO Sydney. 


\section{References}

Australian Broadcasting Corporation. (2007, December 4). ALP education revolution in the spotlight. The 7.30 Report Retrieved from http://www.abc.net.au/7.30/content/2007/s2109329.htm

Bebell, D., \& O'Dwyer, L. M. (2010). Educational outcomes and research from 1:1 computing settings. Journal of Technology, Learning, and Assessment, 9(1) Retrieved from http://ejournals.bc.edu/ojs/index.php/jtla/article/view/1606

Burgad, A. A. (2008). The effects that a one-to-one laptop initiative has on student academic performance and achievement. The University of North Dakota). ProQuest Dissertations and Theses, , 150. Retrieved from http://ezproxy.library.usyd.edu.au/login?url=http://search.proquest.com/docview/304538072?accounti $\mathrm{d}=14757$

CEO Sydney. (2012). role of the catholic education office. Retrieved January 13, 2012, from http://www.ceosyd.catholic.edu.au/About/Pages/Home.aspx\#a_role

Chowdry, H., Crawford, C., \& Goodman, A. (2009). Drivers and barriers to educational success: Evidence from the longitudinal study of young people in England. Institute for Fiscal Studies Retrieved from https://www.education.gov.uk/publications/standard/publicationDetail/Page1/DCSFRR102

Cowie, B., Jones, A., \& Harlow, A. (2011). Laptops for teachers: practices and possibilities. Teacher Development, 15(2), 241-255.

Cuban, L. (2001). Oversold and underused: Computers in the classroom. Cambridge, MA: Harvard University.

DEEWR. (2008a). Computers in schools. Retrieved from http://deewr.gov.au/computers-schools

DEEWR. (2008b). Provision of funding. Retrieved from http://deewr.gov.au/national-secondary-schoolcomputer-fund-provision-funding

Donovan, L., Hartley, K., \& Strudler, N. (2007). Teacher concerns during initial implementation of a oneto-one laptop initiative at the middle school level. Journal of Research on Technology in Education, 39(3), 263-286.

Fullan, M. (2011). Choosing the wrong drivers for whole system reform. Seminar Series Paper No. 204. Retrieved from http://www.michaelfullan.ca/home_articles/SeminarPaper204.pdf

Fullan, M., \& Smith, G. (1999). Technology and the problem of change. Retrieved January 9, 2012, from http://www.michaelfullan.com/media/13396041050.pdf Garthwait, A., \& Weller, H. G. (2005). A Year in the Life: Two Seventh Grade Teachers Implement One-to-One Computing. Journal of Research on Technology in Education, 37(4), 361-377.

Gillard, J. (2008a, February 4). Delivering a digital education revolution. Retrieved from http://ministers.deewr.gov.au/gillard/delivering-digital-education-revolution

Gillard, J. (2008b, June 12). Digital education revolution round one: Delivers more than 116,000 new computers to 896 secondary schools. Retrieved from http://ministers.deewr.gov.au/gillard/digitaleducation-revolution-round-onedelivers-more-116000-new-computers-896-secondary

Gillard, J. (2009, March 31). Additional funding for new computers in 512 schools. Retrieved from http://ministers.deewr.gov.au/gillard/additional-funding-new-computers-512-schools

Goldberg, A., Russell, M., \& Cook, A. (2003). The effect of computers on student writing: A metaanalysis of studies from 1992 to 2002. Journal of Technology, Learning, and Assessment, 2(1). Retrieved from http://ejournals.bc.edu/ojs/index.php/jtla/article/view/1661/

Greaves, T., Hayes, J., Wilson, L., Gielniak, M., \& Peterson, R. (2010). The technology factor: Nine keys to student achievement and cost-effectiveness. Project RED Retrieved from http://www.pearsonfoundation.org/downloads/ProjectRED_TheTechnolgyFactor.pdf 
Gulek, J. C., \& Demirtas, H. (2005). Learning with technology: The impact of laptop use on student achievement. Journal of Technology, Learning, and Assessment, 3(2) Retrieved from http://ejournals.bc.edu/ojs/index.php/jtla/article/view/1655

Hargreaves, A. (1994). Changing teachers, changing times: Teachers' work and culture in the postmodern age. London and New York: Cassell and Teachers College Press.

Hattie, J. (2009). Visible Learning: A Synthesis of Over 800 Meta-Analyses Relating to Achievement. Routledge.

Ingram, D., Willcutt, J., \& Jordan, K. (2008). Laptop initiative evaluation report. Center for Applied Research and Educational Improvement, University of Minnesota Retrieved from http://www.stillwater.k12.mn.us/sites/363874ed-8822-4032-b432366a02d38aa1/uploads/Stillwater_Technology_Report_2.pdf

Kaplowitz, M. D., Hadlock, T. D., \& Levine, R. (2004). A comparison of web and mail survey response rates. The Public Opinion Quarterly, 68(1), 94-101. Retrieved from http://www.jstor.org/stable/3521538

Kulik, J. A. (2003). Effects of using instructional technology in elementary and secondary schools: What controlled evaluation studies say. SRI International Retrieved from http://www.sri.com/policy/csted/reports/sandt/it/Kulik_ITinK-12_Main_Report.pdf

Larkin, K., \& Finger, G. (2011). Informing one-to-one computing in primary schools: Student use of netbooks. Australasian Journal of Educational Technology, 27(3), 513-530. Retrieved from http://ascilite.org.au/ajet/ajet27/larkin.html

Liao, Y.-k. C. (2007). Effects of computer-assisted instruction on students' achievement in Taiwan: A meta-analysis. Computers \& Education, 48(2), 216-233.

Lin, J. M.-C., \& Wu, Y.-J. (2010). Netbooks in sixth-grade English language classrooms. Australasian Journal of Educational Technology, 26(7), 1062-1074. Retrieved from http://ascilite.org.au/ajet/ajet26/lin.html

Miller, R. T. (2008). Laptop educators: Identifying laptop use and pedagogical change (Unpublished doctoral dissertation). The University of Utah, Utah, United States.

Moran, J., Ferdig, R. E., Pearson, P. D., Wardrop, J., \& Blomeyer, R. L., Jr. (2008). Technology and reading performance in the middle-school grades: A meta-analysis with recommendations for policy and practice. Journal of Literacy Research, 40, 6-58. Retrieved from http://jlr.sagepub.com/content/40/1/6

Niles, R. (2006). A Study of the Application of Emerging Technology: Teacher and Student Perceptions of the Impact of One-to-One Laptop Computer Access. Wichita State University.

O'Dwyer, L. M., Russell, M., Bebell, D., \& Seeley, K. (2008). Examining the relationship between students' mathematics test scores and computer use at home and at school. Journal of Technology, Learning, and Assessment, 6(5), 4-45. Retrieved from http://ejournals.bc.edu/ojs/index.php/jtla/issue/view/174

OECD. (2010). Are the New Millennium Learners Making the Grade? Technology Use and Educational Performance in PISA. Paris: OeCd Publishing.

Ottenbreit-Leftwich, A. T., Glazewski, K. D., Newby, T. J., \& Ertmer, P. A. (2010). Teacher value beliefs associated with using technology: Addressing professional and student needs. Computers \& Education, 55(3), 1321-1335. doi: 10.1016/j.compedu.2010.06.002

Owen, A., Farsaii, S., Knezek, G., \& Christensen, R. (2005). Teaching in the one-to-one classroom. Learning \& Leading with Technology, 33(4), 12-16.

Parr, J. M., \& Ward, L. (2011). The teacher's laptop as a hub for learning in the classroom. Journal of Research on Technology in Education, 44(1), 53-73.

Penuel, W. R. (2006). Implementation and Effects Of One-to-One Computing Initiatives: A Research Synthesis. Journal of Research on Technology in Education, 38(3), 329-348. Retrieved 2from http://www.eric.ed.gov/PDFS/EJ728908.pdf 
Piccoli, A. (2011). Government to abolish school certificate. [Press release] Retrieved from http://www.boardofstudies.nsw.edu.au/rosa/pdf_doc/110804-government-to-abolish-schoolcertificate.pdf

Rudd, K., Smith, S., \& Conroy, S. (2007). A Digital Education Revolution. Retrieved from http://www.pixel.com.au/documentation//products/netsupport/netsupport_school/labors_digital_educa tion_revolution_campaign_launch.pdf

Silvernail, D. L., \& Lane, D. M. M. (2004). The Impact of Maine's One-to-One Laptop Program on Middle School Teachers and Students: Phase One Summary Evidence (Research Report \#1). Retrieved from Maine Education Policy Research Institute, University of Southern Maine website: http://www.usm.maine.edu/sites/default/files/Center\%20for\%20Education\%20Policy\%2C\%20Applie d\%20Research\%2C\%20and\%20Evaluation/MLTI_Report1.pdf

Supovitz, J. A., \& Turner, H. M. (2000). The effects of professional development on science teaching practices and classroom culture. Journal of Research in Science Teaching, 37(9), 963-980.

U.S. Department of Education. (2010, September). Evaluation of Evidence-Based Practices in Online Learning: A Meta-Analysis and Review of Online Learning Studies. Washington, D.C. (Contract number ED-04-CO-0040 Task 0006) Retrieved from http:/www2.ed.gov/rschstat/eval/tech/evidencebased-practices/finalreport.pdf

Valiente, O. (2010). 1-1 in education: current practice, International Comparative Research Evidence and Policy Implications. OECD Education Working Papers, 44. OECD Publishing. doi: $10.1787 / 5 \mathrm{kmjzwf19vr2-en}$

Vannatta, R. A., \& Fordham, N. (2004). Teacher dispositions as predictors of classroom technology use. Journal of Research on Technology in Education, 36(3), 253-271.

Vigdor, J. L., \& Ladd, H. F. (2010, June). Scaling the digital divide: Home computer technology and student achievement. National Bureau of Economic Research Working Paper Series, No. 16078 Retrieved from http://www.nber.org/papers/w16078

Warschauer, M., \& Matuchniak, T. (2010). New technology and digital worlds: Analyzing evidence of equity in access, use, and outcomes. Review of Research in Education, 34(1), 179-225.

Weston, M. E., \& Bain, A. (2010). The end of techno-critique: The naked truth about 1:1 laptop initiatives and educational change. Journal of Technology, Learning, and Assessment, 9(6) Retrieved from http://ejournals.bc.edu/ojs/index.php/jtla/article/view/1611/

Windschitl, M., \& Sahl, K. (2002). Tracing teachers' use of technology in a laptop computer school: The interplay of teacher beliefs, social dynamics, and institutional culture American Educational Research Journal, 39(1), 165-205.

Zucker, A. A., \& McGhee, R. (2005). A study of one-to-one computer use in mathematics and science instruction at the secondary level in Henrico County Public Schools. SRI International Retrieved from http://ubiqcomputing.org/FinalReport.pdf

Corresponding author: Simon J. Crook, simon.crook@syd.catholic.edu.au

Australasian Journal of Educational Technology (C) 2013.

Please cite as: Crook, S. J., Sharma, M. D., Wilson, R., \& Muller, D. A. (2013). Seeing eye-to-eye on ICT: Science student and teacher perceptions of laptop use across 14 Australian schools. Australasian Journal of Educational Technology. 29(1), 82-95. 